\title{
Las universitarias en el contexto violento de la Universidad Autónoma de Puebla, UAP, 1972-1973 (Puebla-México)*
}

\author{
Women university students within the violent context in the \\ University of Puebla 1972-1973 (Puebla, Mexico) \\ As universitárias no contexto violento da Universidade Autonoma de \\ Puebla. 1972-1973 (Puebla-México)
}

Recibido el 10 de febrero de 2016. Aceptado el 25 de abril de 2016

\author{
Gloria Arminda Tirado Villegas** \\ México
}

\begin{abstract}
, Para citar este artículo:
Tirado Villegas, Gloria Arminda (junio, 2016). Las universitarias en el contexto violento de la Universidad Autónoma de Puebla, UAP, 1972-1973 (Puebla-México). Ánfora, 23(40),

51-73. Universidad Autónoma de Manizales. ISSN 0121-6538.
\end{abstract}

\section{Resumen}

Objetivo: reconstruir la historia del movimiento estudiantil en el que las universitarias de Puebla (México) participaron en una coyuntura, en la que la izquierda arriba a la dirección de la universidad y se enfrenta a la derecha. Metodología: se utilizó el enfoque de género para visibilizar la presencia de las mujeres, apoyado en documentos, notas periodísticas y entrevistas a algunas participantes. Se apoyó también en la incorporación de la historia oral, en tanto técnica de recuperación y creación de fuentes testimoniales $y$, desde la interdisciplina.

\footnotetext{
* Este artículo es un avance de la investigación "Las universitarias y su participación en el movimiento estudiantil; de 1968 a 1975, Universidad Autónoma de Puebla, UAP", presentada por la autora ante el Seminario Nacional de Movimientos Estudiantiles en el 2014, en la Universidad Nacional Autónoma de México -UNAM-, como parte del proyecto "El movimiento estudiantil mexicano en la construcción del imaginario social. Del desarrollo estabilizador al modelo neoliberal", inscrito en la Dirección General de Asuntos del Personal Académico (DGAPA), Universidad Nacional Autónoma de México (UNAM), Programa de Apoyo a Proyectos de Investigación e Innovación Tecnológica (PAPIIT), clave IG300413. Se inició el 1 de enero de 2014 y está en proceso. Este proyecto es una de las dos líneas que la autora desarrolla con la historia de los movimientos estudiantiles: historia de género e historia social.

** Doctora en Historia. Maestra en Historia. Profesora e Investigadora de la Benemérita Universidad Autónoma de Puebla, México. Correo electrónico: gtirado51@yahoo.com.mx gtiradovillegas@gmail.com
} 
Resultados: se evidenciaron tres momentos claves del año 1973: la creación del Hospital Universitario, la creación de la Escuela Popular de Artes y el día 1o. de mayo, en el que las universitarias participan como actores y/o líderes. Pese a la violencia y persecución del Estado, gobernador y grupos empresariales, las jóvenes coadyuvaron en la construcción de la Universidad de los años setenta. Conclusiones: se valora el tratamiento a las mujeres con estatus similar al de los hombres. Las mujeres participan en las manifestaciones a pesar del discurso de la derecha -en desplegados contra los comunistas- radicalizado en 1972 y en el primer semestre de 1973.

Palabras clave: Universitarias, Movimiento estudiantil, Violencia, Género, Universidad

\section{Abstract}

Objective: to reconstruct the history of the student's movement in which the women students from the University of Puebla (Mexico) participated in that situation, the left wing at the university management faces the right wing. Methodology: gender approach was used to make the presence of women visible. Documents, newspaper articles and interviews to some participants were used as a support; as well as the incorporation of oral history as a recovery and testimonial technique and, from an interdisciplinary perspective. Results: results showed three key moments in 1973, namely, the creation of the University Hospital, the creation of the Popular School of Arts and May first. This day university students participate as actors and/or leaders. Despite violence and persecution of state, governor and business groups, young women collaborated with the construction of the University in the seventies. Conclusions: it is appraised treatment to women with similar men's status. Women participate in demonstrations despite the right wing's speech in -deployed against the communistsradicalized in 1972 and the first half of 1973.

Keywords: Women University students, Student Movement, Violence, Gender, University.

\section{Resumo}

Objetivo: reconstruir a história do movimento estudantil no que as universitárias de Puebla (México) participaram em uma conjuntura; a esquerda acima à direção da universidade se enfrenta à direita. Metodologia: utilizou-se o enfoque de gênero para visibilizar a presença das mulheres, apoiado em documentos, notas de jornais e entrevistas a algumas participantes. Apoiou-se também na incorporação 
da história oral, como técnica de recuperação e criação de fontes testemunhais e, desde a interdisciplinar. Resultados: evidenciaram-se três momentos de grande relevância do ano 1973: a criação do Hospital Universitário, a criação da Escola Popular de Artes e o dia primeiro de maio, dia em que as universitárias participam como atrizes e/ou líderes. Apesar da violência e perseguição do Estado, governador e grupos empresariais, as jovens ajudaram na construção da Universidade dos anos setenta. Conclusões: valoriza-se o tratamento às mulheres com status similar ao dos homens. As mulheres participam nas manifestações apesar do discurso da direita em dispersados contra os comunistas- radicalizado em 1972 e no primeiro semestre de 1973.

Palavras chave: Universitárias, Movimento estudantil, Violência, Gênero, Universidade. 


\section{Introducción}

Unos tres años habían pasado del movimiento estudiantil de 1968 en México -y de aquellos intensos cuatro meses de huelga en apoyo a la UNAM- cuando la confrontación entre la derecha y la izquierda, dentro y fuera de la Universidad, adquirió características más violentas: pasó de las escaramuzas físicas y verbales a los enfrentamientos a golpes, al secuestro y llegó a la represión gubernamental con homicidios. En Puebla, la Iglesia católica tenía mucha influencia y gran parte de la burguesía local profesaba creencias conservadoras; el gobierno en turno y el Partido Revolucionario Institucional -PRI- simpatizaban con esa actitud anticomunista.

Para las mujeres no era fácil ese ambiente característico de una universidad masculinizada y politizada y el constante uso de violencia física entre los grupos estudiantiles. El ascenso de la izquierda en la Universidad era el telón de fondo de esta polarización: integrantes del Partido Comunista dominaban; los grupos conservadores exigían al gobernador que frenara a los estudiantes que se radicalizaban; los desplegados de plana completa firmados por el Consejo Coordinador Empresarial exigían al gobernador que frenara el caos comunista (El Sol de Puebla, 1973, p.11). El gobierno, estatal y federal, presionaba o castigaba a la institución entregándole subsidios insuficientes para el desempeño de sus actividades. Esta situación unió a estudiantes, docentes y trabajadores universitarios, de izquierda y no. Y más aún porque los docentes y trabajadores no recibían su salario a tiempo y la matrícula escolar había aumentado; era difícil tener una planta de profesores dedicada profesionalmente a la enseñanza.

El movimiento universitario se planteaba, entonces, renovar la planta académica, cambios en los programas de estudio y la desaparición de la Junta Administrativa de Gobierno, por lo que en 1971, cuando se efectuaron las elecciones para consejeros, los estudiantes democráticos (de la Central Nacional de Estudiantes Democráticos), los identificados con la izquierda (comunistas, maoistas) y de los comités de lucha, lograron ganar consejerías e impulsaron como rector al químico Sergio Flores Suárez, militante del Partido Comunista Mexicano, (PCM).

La derrota de los integrantes del Frente Universitario Anticomunista (FUA) en adelante) fue un detonante, ya que los impulsó decididamente a confrontarse con sus contrincantes. El 10 de junio de 1972 el químico Sergio Flores Suárez fue 
designado rector interino de la Universidad Autónoma de Puebla; en septiembre ganó las elecciones y se convirtió en rector electo.

Las universitarias participaron en este movimiento estudiantil que duró varios años. Qué hacen, quiénes son y por qué se visibilizan son las preguntas que guían este texto, cuyo objetivo es reconstruir historias no contadas en las que las mujeres develen su presencia. Así, sólo se abordarán tres momentos representativos en 1973, en los que se puede evidenciar cómo y por qué las mujeres participaron en el movimiento.

El objetivo, entonces, de este trabajo es el análisis del proceso del movimiento estudiantil en el que las universitarias participaron de diferentes formas. La transversalidad de género lleva a nuevas reflexiones sobre lo escrito de este movimiento estudiantil en el que se cree que prevalecieron los varones como representantes de la comunidad estudiantil. Se recurre aquí al uso de la historia oral con el fin de conocer más ampliamente cómo fue la participación femenina.

Es importante anotar que en México la Universidad Autónoma de Puebla no es la única donde la izquierda ascendió a la dirección de una universidad; lo logró además en la UNAM (Rivas, 2007) en la Universidad Autónoma de Sinaloa, en la Universidad de Sonora y en la Universidad Autónoma de Guerrero, por ejemplo.

En este escenario de violencia anticomunista las estudiantes participaron pese a lo que pudiera ocurrirles en los recintos universitarios y en los espacios públicos. En otros ensayos (Tirado, 2004/2014, pp. 373 - 389) se ha abordado la intensa participación de las mujeres en este movimiento estudiantil que generó su proceso de empoderamiento, cuando arribaron a diferentes espacios académicos y administrativos de la Universidad Autónoma de Puebla.

Conviene precisar que los estudios desde esta óptica comenzaron a realizarse hace unas décadas y, aunque siguen siendo escasos, se han centrado más en el 68. Entre las pioneras se encuentra Tirado (2004); y la historiadora Mayra Lizzete Vidales Quintero quien impulsa una investigación sobre las universitarias en el movimiento estudiantil de los setenta en la Universidad Autónoma de Sinaloa (Vidales, 2015, p. 299-311).

Durante el periodo que analiza el presente trabajo, estudiosos del movimiento estudiantil en Puebla como Humberto Sotelo Mendoza (2002) y Alfonso Yánez Delgado (1988), evidenciaron la violencia de Estado hacia la Universidad y narraron los enfrentamientos entre izquierda y derecha. Sin embargo, a pesar de 
su valor testimonial, no abordan la riqueza del propio movimiento estudiantil en el que muchos jóvenes se formaron e hicieron aportes al crecimiento institucional; sin los recursos necesarios vencían rémoras durante esos años.

Una característica sustantiva fue la presencia de las universitarias; su inclusión fue el plus en este proceso; su participación enriqueció el movimiento porque muchas de ellas se desempeñaron en actividades académicas e institucionales y otras en actividades culturales, como el teatro, la música, la fotografía; algunas de ellas empieza a militar en la amplia gama de organizaciones políticas y sociales de izquierda.

Si bien los estudios sobre la participación de las mujeres se están realizando para reconocerlas, debe partirse no del concepto de líderes, sino del de activistas; desde allí conocer quiénes eran, qué hacían, cuál era su papel en el movimiento y reconstruir su participación durante el movimiento estudiantil conocido como la segunda Reforma Universitaria. Este texto pretende visibilizarlas en la complejidad de un ambiente plagado de enfrentamientos, de violencia verbal y discursiva en el que ellas tomaron decisiones centrales, desde a quién apoyar en la Universidad hasta cómo concretar su compromiso social. El interés por este tema es aportar a la historia de las mujeres, como al de la propia institución universitaria.

\section{Metodología}

En México, el movimiento del 68 concentró la mirada de los estudiosos del movimiento estudiantil: la violación a la autonomía universitaria y lo ocurrido el 2 de octubre llevó a exigir esclarecimiento y justicia; la mayoría de investigaciones analizan más la participación de la UNAM y recientemente se conocen investigaciones y testimonios de los estudiantes del Instituto Politécnico Nacional, IPN. Es en recientes décadas cuando surgió un mayor interés por analizar lo ocurrido en otros Estados del país como Puebla, Guerrero, Sinaloa, Sonora, Morelia, Oaxaca, San Luis Potosí y están en construcción más historias con un enfoque regional ${ }^{2}$. Con las nuevas investigaciones se constata el enriquecimiento que generó la historia regional porque posibilita una historia

2. Fue notorio en las ponencias presentadas en el Congreso Internacional sobre Movimientos Estudiantiles "A 45 años del 68", organizado por el Seminario Nacional de Movimientos Estudiantiles Mexicanos, BUAP, ICSyH, en Puebla, del 21 al 25 de octubre de 2013. 
comparativa entre estos movimientos, cuyas sincronías y diferencias ofrecen otras interpretaciones.

La historia regional amplía el panorama de un proceso y la historia de género, permite mostrar la diversidad de comportamientos con diferencias políticas y culturales y dar cuenta del proceso de inclusión de las estudiantes. Es decir, ayuda a visibilizar a las jóvenes y sus prácticas culturales en el movimiento estudiantil del periodo analizado. Al mismo tiempo permite reconstruir, mediante una visión fresca, aspectos con los que la perspectiva de género rescata detalles significativos que escapan a la historia tradicional del movimiento estudiantil, en el que los líderes (hombres, por supuesto) son los protagonistas y quienes articulan la trama de los conflictos políticos, de persecución, de clandestinidad y hasta de lo anecdótico: los encuentros con los porros, los resabios de viejas rencillas $y$, sobre todo, la experiencia de la militancia política.

La categoría de género permite analizar la información y entender las diferencias entre los y las jóvenes. Se entiende por género la definición de Joan Scott:

El núcleo de la definición reposa sobre una conexión integral entre dos proposiciones: el género es un elemento constitutivo de las relaciones basadas en las diferencias que distinguen los sexos y el género es una forma primera de relaciones significantes de poder. Los cambios en la organización de las relaciones sociales corresponde siempre a cambios en las representaciones del poder, pero la dirección del cambio no es necesariamente en un sólo sentido (Scott, 1996, p. 286).

Este trabajo sobre la participación de las mujeres en el movimiento estudiantil universitario de Puebla, con perspectiva de género, se apoya en las fuentes documentales y en la historia oral. Se ha partido de la utilización de entrevistas a universitarias, realizadas tiempo atrás, para crear el corpus. Se partió de un cuestionario semiestructurado y dividido en bloques de preguntas: infancia, ingreso a la educación superior y participación en el movimiento. Se partió del concepto de activistas, no el de líderes, para incluir a la mayoría de estudiantes; además porque ellas expresaban sentirse "de la base". Sobre el uso de fuentes orales para la historia de las mujeres se ha escrito un texto (Tirado, 2014, pp. 113-148), y las entrevistas se han compilado en un libro titulado Volver a los diecisiete... Testimonios de las estudiantes que participaron en movimientos estudiantiles de la Universidad Autónoma de Puebla, (2015). 
Se parte del hecho de que los testimonios individuales y subjetivos de la historia oral son instrumentos clave para desentrañar la compleja relación entre el proceso social y la vida individual en un momento histórico determinado. Permiten acercarse a la dicotomía entre lo público y lo privado (Cano, 1994, p. 418) y la información vertida en estas entrevistas se analizaron buscando en los relatos los momentos difíciles que ellas sortearon, cruzando sus experiencias políticas y conocer cómo interiorizaron los conflictos causados por la confrontación entre las dos posiciones polarizadas. La versión de ellas ayuda a contrastar, también, lo publicado en la prensa.

\section{Resultados}

Las nuevas habilidades no fueron desaprovechadas. Fueron las mujeres que se estaban formando en la Universidad de los últimos setenta las que protagonizaron la revuelta feminista que inició la tercera ola [del feminismo]

(Valcárcel, 2012, p. 135).

A continuación se presentan tres momentos en los que se evidencia la participación de las universitarias: la creación del Hospital Universitario, la creación de la Escuela Popular de Artes y el 1o. de mayo de 1973 (incluye la creación de la Universidad Popular Autónoma del Estado de Puebla). Son momentos que agudizaron los enfrentamientos entre los dos grupos ideológicamente enfrentados, los conservadores o FÚAS y los de esa amplia izquierda. En cada uno se define el contexto y se encontró, a través de las entrevistas, cómo participaron y por qué era difícil para las universitarias vencer las ideas que prevalecían sobre lo que era la universidad calificada por la derecha como nido de comunistas. Las estudiantes rompieron con los estereotipos y en el momento en que los FÚAS plantearon la división, muchas continuaron sus estudios en la UAP.

La aseveración de Valcárcel (2012) se corrobora con la realidad de la Universidad Autónoma de Puebla. En efecto, las universidades públicas pasaban por un proceso de masificación como el que alcanzó la UAP, una de las razones por las que su situación económica era precaria: el número de estudiantes matriculados se incrementó de tal manera que al finalizar el periodo rectoral del químico Sergio Flores Suárez había 22.585 estudiantes. De su informe se desprenden los siguientes datos comparativos: 
en 1972, fecha en que inicia el periodo del informe, había 17.207 estudiantes inscritos; 18.645 alumnos en 1973 y 22.585 en 1974 (Flores, 1975, p. 13).

También creció el número de escuelas: en junio de 1972 existían doce carreras y especialidades universitarias; en 1975 eran 30 las carreras y especialidades. Se crearon las carreras de Matemáticas, Computación, Electrónica, Ingeniería Topógrafica y nuevas preparatorias regionales y en la ciudad. La Universidad vio ampliada su estructura académica con el Hospital Universitario, la Escuela Popular de Artes, la Escuela de Veterinaria y Zootecnia, el Centro de Cálculo Joel Arriaga Navarro³. Además, se establecieron importantes departamentos administrativos: Información y Relaciones; Publicaciones, Personal, Extensión Universitaria, Servicio Social, Microfilmación.

Lamentablemente la información sobre la matrícula escolar no está desagregada por sexos, limitante para conocer cuántas mujeres estudiaban por escuela, aunque se supone que la proporción continuaba siendo asimétrica. En Medicina, por ejemplo, "la carrera más solicitada por mujeres", en 1971 estudiaban 1.914 hombres y 588 mujeres (El Sol de Puebla, 197 1, 4 de agosto) y en Ingeniería Civil, una de las carreras masculinizadas, la primera mujer ingresó en 1971. Esto lleva a presumir que había carreras feminizadas, como Enfermería, Comercio y Ciencias Químicas, que lo eran también porque las jóvenes podían egresar como técnicos medios e iniciar su vida laboral. La distribución de la matrícula por carreras también expresaba una situación generalizada en otras instituciones de educación superior. Es aquí donde se evidencian algunas transformaciones interesantes relacionadas con la inserción de las jóvenes en el movimiento que se gestaba, pese al ambiente adverso y el cuestionamiento a la Universidad, por los grupos conservadores.

Dos hechos marcaron la violencia que alcanzaría a estudiantes de una universidad que transitaba hacia la Segunda Reforma Universitaria: los asesinatos del arquitecto Joel Arriaga Navarro, el 20 de julio de 1972, cuando era director de la Preparatoria Nocturna Benito Juárez ${ }^{4}$ y el de Enrique Cabrera Barroso, jefe de Extensión Universitaria, asesinado al llegar a su casa el 20 de diciembre de 1972. El clima

\footnotetext{
3. El Consejo Universitario aprobó que el Centro de Cálculo llevara el nombre de Joel Arriaga Navarro, en homenaje a quien fue asesinado el 20 de julio de 1972.

4. Joel fue el único preso político de Puebla; desde octubre de 1968 permaneció en la cárcel de Lecumberriy salió en 1971 junto con los demás presos. En 1972 fue nombrado director de la Escuela Preparatoria Benito Juárez y su prestigio entre estudiantes y maestros lo hacían particularmente blanco del odio reaccionario. Joel era integrante del Partido Comunista; poco antes de su muerte, en las paredes de edificios de la ciudad aparecieron volantes y pintas donde se atacaba calumniosamente a los nuevos funcionarios. Joel, además, había sido maestro en la Escuela de Arquitectura, donde los FÚAS dominaban hasta cierto punto.
} 
de violencia alteró aún más las relaciones cotidianas dentro y fuera de las aulas universitarias.

Diferentes grupos de estudiantes actuaban en la Universidad, además de los comités de lucha, organizados desde el movimiento estudiantil de 1968 y otros más que surgieron en los primeros años de los setenta. Los enfrentamientos se volvieron continuos, primero entre grupos de la Escuela de Derecho y de la Escuela de Economía; después en las escuelas de Arquitectura y Administración de Empresas, entre los comités de lucha contra los FÚAS. Los choques se recrudecieron en 1972 con las elecciones para rector, proceso que ganó el químico Sergio Flores Suárez apoyado por un grupo en el que confluyeron diversas corrientes democráticas y de izquierda.

Es en este proceso, llamado Segunda Reforma Universitaria ${ }^{5}$, en el que las universitarias participaron activamente y de diferentes formas: en los comités de lucha; como consejeras universitarias estudiantes o profesoras; en los distintos organismos de izquierda que se formaban y en las actividades culturales desplegando diferentes iniciativas. Atendiendo al espacio con el que se cuenta para este artículo señalaré tres acciones y momentos importantes de esos años: la incorporación del Hospital Universitario, la creación de la Escuela Popular de Artes y la represión del 1o de mayo de 1973.

\section{El Hospital Universitario}

Antes de 1973 los estudiantes de la Escuela de Medicina realizaban sus prácticas y el servicio social en el Hospital Civil de Puebla, nosocomio que dependía del gobierno del Estado y estaba un tanto descuidado. Como las corrientes democráticas universitarias plantearon la necesidad de modificar el modelo educativo, los estudiantes del comité de lucha de la Escuela de Medicina solicitaron que ese hospital fuese incorporado a la Universidad para sustentar el hospital-escuela. Aunque el decreto de cesión fue emitido por el gobierno del Estado el 16 de octubre de 1972, no fue nada fácil iniciar las actividades del ya denominado Hospital Universitario. Martha Curro Castillo, una de las más conocidas activistas de Medicina, con sus compañeras luchó para que el Hospital Civil pasara a la Universidad:

\footnotetext{
5. Se le llama Primera Reforma Universitaria al proceso del movimiento estudiantil de 1961, que logró el cambio de la Ley Orgánica de la Universidad Autónoma de Puebla (1963), en el que por primera vez la elección de las autoridades la harían los universitarios y no el gobernador.
} 
"Entre 72 y $73 \ldots$ estábamos en la lucha por lo del Hospital Universitario, nos vinculamos en las manifestaciones, en las marchas; en la etapa que yo te digo era común ver rodeada la Universidad por el ejército, fue cuando Bautista O'Farril era gobernador. En mi ámbito participé en el movimiento de la Escuela, participé en el movimiento universitario" (Curro, 2001, noviembre 18).

No era la primera ocasión en la que Martha participaba; ella egresó de una preparatoria del interior del Estado de Puebla, de Tehuacán, y cuando en 1971 quiso presentar su examen de ingreso se le negó, como a muchos aspirantes foráneos. Decidió unirse a "los fuereños" y luchar por la ampliación del cupo de matrícula. Así, logró ingresar a la Escuela de Medicina; esta lucha la marcó políticamente. Con esos ideales participó en el comité de lucha de la Escuela de Medicina y pronto se relacionó con miembros de otros comités de lucha. Compartir decisiones e ideas le permitía un constante enriquecimiento de experiencias que se combinaban con propuestas académicas y políticas, de las que podía nutrirse: ¿cómo debía funcionar el Hospital Universitario? ¿Cómo y por qué debía ser hospital-escuela? ¿Cómo debían practicar los estudiantes? ¿Cómo atraer a los estudiantes e interesarlos en apoyar al hospital-escuela?

En ese contexto de negociación y presión al gobierno para incorporar el Hospital Universitario se formó ella y su generación. A los primeros docentes no les pagaron sus salarios por un tiempo hasta que todo quedó regularizado. No sólo había que convencer a los estudiantes de esta lucha sino a la misma sociedad, que diariamente escuchaba noticias donde se atacaba a la Universidad.

Martha recuerda lo valioso que era definirse y entre las compañeras más combativas menciona a Rosa Márquez Cabrera, quien era integrante de la Juventud Comunista. Rosi, como la llama Martha, era la compañera oradora:

"Era la única mujer que subía al estrado a hablar. Rosi tenía mucho apoyo; ya después nosotros con Sergio Flores y el Ingeniero Terrazas, lo tuvimos. Ella con el grupo de "los puros"6 tenía más influencia. Pero de las mujeres yo creo que fue entre dirigente y activista; era de las pocas que participábamos porque no éramos muchas" (Curro, 2001, noviembre 18).

6. Les Ilamaron los puros al grupo dirigente de la Juventud Comunista en Puebla, quienes tenían el predominio del poder. 
El Hospital Universitario se convirtió en una institución referente porque atendía a población de escasos recursos, a enfermos graves, a accidentados, incluso a mujeres pobres que en condiciones de parto llegaban por urgencias. Además, empezó a atender la salud de los trabajadores universitarios.

\section{Escuela Popular de Artes}

El segundo momento al que se hace referencia es la creación de la Escuela Popular de Artes. En sesión ordinaria del 26 de septiembre de 1973 se presentó una carta firmada por miembros del Instituto de Artes Plásticas de Bellas Artes del Estado el 12 del mes en curso y cuatro anexos del Comité de Lucha. En esta carta solicitaban que ese Instituto pasara a formar parte de la Universidad Autónoma de Puebla, ya que la Ley Orgánica de la Universidad de Puebla, expedida el día 21 de mayo de 1937, señalaba en el capítulo segundo referente a la constitución de la Universidad, que la Escuela de Bellas Artes le pertenecía a la institución universitaria. Por mayoría de votos se aprobó la integración del Instituto de Artes Plásticas de Bellas Artes del Estado a la Universidad (ACU, 1973, septiembre 26). Con base en esta incorporación se creó la Escuela Popular de Artes (EPA).

La creación de la Escuela Popular de Artes no fue decisión de las autoridades del gobierno, sino una demanda de los estudiantes. Esta escuela pretendía formar artistas con la participación de profesores de la Ciudad de México. Un testimonio sobre esta iniciativa lo ofrece Norma Navarro Silenciario, quien contaba con 17 años cuando ingresó, en enero de 1973, a la Preparatoria Popular Emiliano Zapata de la Universidad. Ella había estudiado la secundaria en la escuela de monjas Enrique Benítez; su ingreso a la Universidad le dio un viraje a su formación y concepción del mundo. No es extraño que le sorprendiera ver la independencia con que se manejaban "los chavos", escuchar cómo hablaban, sus consignas y la propaganda que hacían y, por supuesto, ver el edificio Carolino lleno de pintas, más aún en las "catacumbas", donde funcionaba "La Pop", como le decían en el argot estudiantil a la Preparatoria Popular Emiliano Zapata. En todo el Carolino y a toda hora había actividades, aun durante la noche. Recuerda Norma:

"Fue un mundo nuevo para mí, me atraía ese ambiente de libertad (...) Eran tiempos de mucha efervescencia política, en los que, como jóvenes estudiantes estábamos llenos de ímpetus y esperanza, motivados por los movimientos que en la década de los setenta luchaban contra el autoritarismo y la "guerra sucia" del régimen.

7. Entrepiso que está en el tercer patio del edificio Carolino; se decía que fueron celdas de retiro o castigo de los monjes jesuitas. 
Queríamos cambiar el mundo, el país y, en particular en Puebla, un Estado represor (...) Además, en esa edad eres aún más romántico en la lucha. Participábamos en manifestaciones por la defensa de la autonomía, por el aumento de subsidio y en apoyo a todas las causas populares que creíamos justas. Siempre estuve convencida de que era importante involucrarme, comprometerme, ni siquiera pensaba en lo peligroso que podía ser en ese ambiente lleno de provocaciones; así como había gente consciente, positiva, había porros" (Navarro, 2012, mayo 22).

Y continúa su testimonio:

"Ese mismo año (1973) tenía poco tiempo de haber conocido a Enrique Condés Lara, cuando a petición de algunos estudiantes inconformes con el autoritarismo del director de la Escuela de Bellas Artes nos pidieron apoyo para destituirlo. Para hacerlo más "legal”, acordamos inscribirnos como alumnos y en septiembre decidimos realizar la toma. Recuerdo que ese día llegué con Enrique y otros compañeros; subimos a la dirección y le avisamos al director que a partir de ese momento estaba destituido y que, mientras tanto, nosotros nos haríamos cargo también del edificio" (Navarro, 2012, mayo 22).

Desde ese momento la EPA se convirtió para Norma, y varios estudiantes, en un segundo hogar, un espacio de libertad, de propuestas, de contacto con grupos que llegaban a estudiar. "Era fabuloso sentir que dirigía algo", dice Norma, y "a veces me quedaba a dormir sin importarme las incomodidades", eso era: se habían convertido en una especie de centinelas, del cuidado de las valiosas pinturas que estaban ahí.

\section{El Primero de mayo de 1973}

Parecía que la creación de cada dependencia y su reconocimiento dentro de la Universidad, y después por la Secretaría de Educación Pública, era motivo de disputas y enfrentamientos. En varias ocasiones el ejército permanecía vigilando la ciudad, rodeando el Carolino. En 1973, en la Universidad Autónoma de Puebla estudiaban 18.645 alumnos (El Sol de Puebla, 1973, p. 5). Los conflictos se fueron agudizando hasta llegar al 1o de mayo, con el asesinato, por francotiradores, de cuatro estudiantes y un vendedor de fruta.

Como ya se mencionó, en esa época en las escuelas de Arquitectura y Administración de Empresas se concentraban grupos polarizados de FÚAS y de Reforma Universitaria. Por otra parte, en el grupo reformista universitario hubo un rompimiento con profesores y estudiantes que eran del PRI, conocidos como del Grupo de 64. Humberto Sotelo describe las razones, y afirma que, cuando el movimiento se radicalizó, el Grupo 64 intentó someter al grupo de 
Reforma Universitaria y hace explícita su relación con el gobernador Gonzalo Bautista O'Farril (Sotelo, 2002, p. 79). Esta ruptura tendría consecuencias al expulsar al grupo priista de la Universidad y, al mismo tiempo, ocurre el ascenso de las fuerzas de izquierda en ella. Pero en 1973 el enfrentamiento se produce entre los FÚAS y la corriente de Reforma Universitaria, un grupo amplio con diferentes objetivos e ideas.

En las secciones culturales de la prensa local aparecían numerosas notas sobre actividades culturales universitarias y en los recintos de la Universidad se vivía una aparente calma. Cotidianamente había diversas actividades; por ejemplo, quienes asistían al Cine Club Universitario veían películas en el Salón de Proyecciones del edificio Carolino, al que después del golpe de Estado en Chile le pusieron el nombre de Salvador Allende. Sin embargo, esta información era desplazada por las notas que El Sol de Puebla y Novedades publicaban en las primeras planas: "Zafarrancho en la Universidad", "Fuera los comunistas".

Mientras, en las notas culturales universitarias pasaban desapercibidas en las páginas interiores y en las últimas se publicaban notas breves sobre la titulación de algún estudiante ${ }^{8}$ o información de ligas deportivas donde los equipos de la UAP participaban. Toda esa nutrida vida interna de los universitarios se ignoraba porque en sus primeras planas los periódicos encabezaban con estilo de nota roja los conflictos. Generalmente la población se guiaba por la prensa.

Por fortuna el fondo fotográfico "Vida Universitaria", resguardado en el Archivo Histórico de la BUAP, con 650 imágenes, ayuda a recuperar una historia a través de fotografías tomadas, no por reporteros profesionales sino por los propios universitarios, como servicio a la comunidad y cuyo único propósito era dejar evidencia de lo que hacían, fuesen actividades festivas, culturales o manifestaciones. La mayoría de estas imágenes muestran una vida cultural muy activa en la institución y el papel del Departamento de Extensión Universitaria, que en el ámbito cultural y artístico fue sobresaliente.

Era común que llevaran a escuelas de la UAP o al interior del Estado grupos culturales, de música, de teatro, cuando entonces ninguna institución gubernamental lo hacía; que invitaran a dar conferencias o recitales a personajes

8. El 18 de mayo de 1973, en El Sol de Puebla aparecía "Se titularon 40 enfermeras", nota que pasó desapercibida y empequeñecida al lado de desplegados de media plana en contra de los comunistas que se apoderaron de la Universidad. 
como Carlos Monsiváis, José Revueltas, Efraín Huerta, Ernesto Cardenal, José Emilio Pacheco, o al obispo Sergio Méndez Arceo.

Esta dinámica cotidiana con propuestas innovadoras de teatro, literatura, pintura, gráfica, cine, fotografía, era guiada por el interés de actualizar los vínculos artísticos y culturales de la Universidad e impulsada por estudiantes y profesores universitarios. En este periodo el primer director del Departamento de Difusión Cultural de la UAP fue el premio nacional de poesía Óscar Oliva y después lo sería el escritor y crítico literario Emmanuel Carballo.

Así, pese a la tensión cotidiana que se vivía por los conflictos internos que se han referido, a la intervención beligerante de organizaciones patronales, como el Consejo Coordinador Empresarial, y de los llamados del propio arzobispo de Puebla, Octaviano Márquez y Toriz, y de organizaciones ciudadanas que aparecían de la noche a la mañana, un ambiente de libertad creativa y de compromiso con la defensa de la Universidad alentaba a los universitarios a seguir laborando.

Una prueba era la consolidación del Coro Universitario. El 5 de marzo de 1973 el maestro Felipe Calderón (director del Coro) envió, al entonces rector de la Universidad, químico Sergio Flores Suárez, una solicitud con el proyecto de creación de un Departamento de Música de la UAP y el 14 de marzo de ese año se resolvió positivamente y quedó aceptado. El 1 de mayo de 1973, cuando policías francotiradores asesinaron a estudiantes, el Coro Universitario tenía una presentación; varias estudiantes que participaban en él debieron cancelarla para auxiliar a los jóvenes heridos y a quienes llegaban con convulsiones causadas por los gases lacrimógenos. Por la dimensión de la violencia ocurrida el 1o de mayo de 1973 y sus repercusiones, en este estudio se enfatiza este acontecimiento.

Los sucesos iniciaron en el desfile oficial que cada año conmemora el Día del Trabajo; entonces los contingentes que desfilaban salían de la 25 Poniente y 11 Sur. Al final de la columna oficial se integraron los contingentes independientes: profesores normalistas del Movimiento Revolucionario del Magisterio, ferrocarrileros, universitarios, vendedores ambulantes, campesinos... Cuando brigadas de estudiantes universitarios repartían volantes entre los asistentes al desfile varios fueron detenidos, acaso cuatro, aunque El Sol de Puebla registra once.

Por esta detención algunos estudiantes se trasladaron al edificio Carolino para avisar de lo ocurrido. La tensión no quedó ahí porque cuando la columna independiente estaba por pasar frente al gobernador los granaderos lanzaron gases lacrimógenos y dispersaron a sus integrantes. Algunos corrieron y se fueron a sus casas; otros se refugiaron en el edificio Carolino (sede de la Rectoría), varios de ellos afectados por los gases lacrimógenos. 
Al conocer la detención de sus compañeros, algunos jóvenes decidieron retener a un policía y canjear su liberación por la de los universitarios detenidos en el desfile; otros quemaron una patrulla de la policía en la 4 Norte y Avenida Maximino Ávila Camacho (esquina del edificio Carolino). Minutos después se escucharon detonaciones que provenían de edificios aledaños a la Universidad, incluso de una torre de la Catedral, (a dos calles del edificio central). Alguien alcanzó a tomarle una fotografía a quien disparaba desde ahí. Las balas son certeras, son disparadas con precisión por armas de alto poder. Como consecuencia del ataque mueren cinco personas, cuatro estudiantes y un comerciante ambulante de frutas que vendía en las afueras del edificio Carolino.

Algunos estudiantes que permanecían en el interior del Carolino de inmediato salieron y grabaron escenas de lo ocurrido. Por la situación que se vivía había interés en registrar testimonios, tomar imágenes de momentos álgidos, violentos, peligrosos. Aunque hubo varios universitarios comprometidos, se desconoce qué ocurrió con esas imágenes ${ }^{9}$.

Silvia Guadalupe Cano González, por ejemplo, cuando ingresó a la Universidad a estudiar Economía decidió entrar también al Taller de Cine para tomar clases de fotografía. El taller pertenecía al departamento de Difusión Cultural y estaba vinculado a Extensión Universitaria. Ella tomó algunas fotografías del 1 de mayo de 1973, su testimonio es valioso:

"Nos dividíamos los trabajos: unos muchachos se iban a tomar fotos al desfile mientras otros nos quedábamos a pasar películas relacionadas con el 68 , con cuestiones de avanzada, movimientos que eran poco conocidos por la ciudadanía. Ese día nos tocó pasar películas en el Salón Barroco a un grupo de compañeros. Manejábamos un proyector antiguo de 16 milímetros y previamente habíamos invitado a padres, a mamás de los estudiantes de la Universidad; llegaron con sus niños a ver las películas que pasábamos. Había mucha comunicación entre

\footnotetext{
9. Los miembros de este taller eran estudiantes de diferentes escuelas de la Universidad; filmaron y fotografiaron los hechos del 10 de mayo de 1973. Con el material fotográfico y filmado realizaron un documental que incluye escenas correspondientes a la reacción de los universitarios cuando se conoció la renuncia del gobernador Gonzalo Bautista. Este documento fílmico se exhibió varias veces y en distintos lugares; luego se extravió y a la fecha algunos fragmentos de la película se han integrado a otros documentales. Estos materiales gráficos contribuyeron a desmontar la versión oficial del gobierno poblano, que responsabilizaba a los universitarios de los acontecimientos, incluso de la muerte de los estudiantes, que fueron literalmente cazados por policías francotiradores. Una de las escenas del documental corresponde al momento en que el profesor Alfonso Calderón es herido en la esquina de las calles Maximino Ávila Camacho (hoy Juan de Palafox y Mendoza) y 4 Norte, después fallecería en el Hospital Universitario.
} 
padres e hijos en ese ámbito universitario. Los muchachos preparatorianos hacían participar a sus padres; tenía que ver con la vinculación muy fuerte del pueblo con la Universidad. Venían vecinos del Carolino, gente de todo nivel, de toda clase o de toda condición económica. No llenamos el Barroco pero sí había bastantes familias" (Cano, 2005, junio 6).

Silvia Guadalupe estudió la preparatoria en el Instituto de Ciencias Agrícolas, una escuela particular, y cuando en 1973 entró a estudiar Economía, donde había un activo Comité de Lucha, pronto se interesó por colaborar a través del registro gráfico del movimiento. Captó imágenes de policías disparando gases lacrimógenos que entraban por ventanales del edificio, que ocupa una cuadra completa, y sobre todo al segundo piso, donde ella se encontraba. Mientras, desde la azotea los jóvenes aventaban piedras y bombas molotov que no lograban llegar a su objetivo.

La versión de la prensa reportó los hechos como "Balacera entre estudiantes", pese a que se registraron imágenes de los policías:

Tres muertos y doce lesionados, graves, entre ellos cuatro policías uniformados, es el saldo del enfrentamiento ocurrido ayer a las 11:40 de la mañana, entre un grupo estudiantil que se parapetó en las azoteas del edificio carolino de la UAP, en el templo de La Compañía, y el hotel Colonial, contra elementos de la policía que habían recibido la orden de acordonar la Universidad (El Sol de Puebla, 1973, mayo 2$)$.

El testimonio de Silvia Guadalupe describe otro momento de ese día:

"Mi compañero Toño Robledo, que estaba ayudando con lo de la fotografía, me dijo, "vamos a ver si tomamos fotos; hay que tomar fotos. ¿Por dónde salimos? Vamos a ver qué pasa. Vamos por el Salón de Banderas. A ver qué fotos podemos tomar desde el balcón del Salón de Banderas -que daba a la calle Maximino Ávila Camacho-". Salimos a ver qué pasaba. Vimos que era un peligro lo que estábamos haciendo porque asomábamos la cabeza y sentimos como las ráfagas de balas nos pasaban muy cerca (...) Salimos del Barroco y fuimos a los corredores del Carolino y lo mismo. Era peligroso estar ahí porque los corredores del Barroco están llenos de ventanales y por ahí podría llegar una bala perdida. Nos volvimos a meter al Barroco y tratamos de estar lo más tranquilos posible. Debo decir que los gases lacrimógenos entraban hasta el Barroco, entraban al Carolino, sentíamos que nos picaban los ojos" (Cano, 2005, junio 6). 
La memoria se expresa de manera individual y subjetiva a partir de las experiencias propias de los actores. La memoria del movimiento estudiantil que se gestó en esos años incluye relatos de las testigos. Esto es importante tenerlo presente porque aunque la narración testimonial habla de una participación individual, incluye tácitamente la experiencia colectiva de la organización en la que cada sujeto participa.

La violencia del 1o de mayo cohesionó a los estudiantes y la Universidad debía defender su autonomía, exigir justicia por los muertos y heridos y defenderse de las acusaciones de que era objeto. Ante lo ocurrido se citó a los consejeros a reunión extraordinaria del Consejo Universitario el 3 de mayo; en ella, se acuerda por unanimidad declarar a Gonzalo Bautista O'Farril, gobernador del Estado, "hijo indigno de la institución” y solicitar públicamente su destitución.

El licenciado Luis Echeverría Álvarez, presidente de la República, aceptó esta petición ante las evidencias de la intervención del gobierno estatal en los hechos y frente al riesgo inminente de que enfrentamientos mucho más graves ocurrieran por las nutridas manifestaciones universitarias y por las expresiones violentas y laudatorias con que los grupos conservadores del Estado apoyaban las acciones del gobernador. Así, ante el Congreso del Estado, Gonzalo Bautista O'Farril presentó su renuncia a la gubernatura. Era el segundo gobernador consecutivo que caía en Puebla $^{10}$ (ACU, sesión del 3 de mayo de 1973, pp. 33-42).

Los grupos empresariales progubernamentales, como el Consejo Coordinador Empresarial y el Comité Coordinador de la Ciudadanía del Estado de Puebla, publican desplegados de plana completa en El Sol de Puebla para oponerse a la renuncia del gobernador Gonzalo Bautista O'Farril y citan a una manifestación para el 11 de mayo. También apareció un desplegado firmado por madres de familia contra la dimisión del gobernador Gonzalo Bautista. Sin embargo el 10 de mayo, en el Congreso local los diputados aprueban la renuncia. Por su parte el arzobispo de Puebla, Octaviano Márquez y Toriz, invita a la población a "orar para que cese la violencia":

El Arzobispo de Puebla exhortó a los católicos poblanos a orar por México, en plegarias públicas y personales, para obtener la paz cristiana, el amor fraterno, la concordia y la unión de todos los mexicanos, en momentos en que "nuevos

10. En 1964 había sido destituido como gobernador el general Antonio Nava Castillo a causa de un movimiento de productores lecheros que se gestó por la decisión de apoyar la instalación de una pasteurizadora, cuando en la ciudad se tomaba leche bronca. El movimiento fue apoyado por el movimiento estudiantil. 
sucesos dolorosos han venido a ensangrentar y conmover a nuestra amadísima ciudad y frente a las demás perturbaciones que se vienen sintiendo desde hace tiempo (El Sol de Puebla, 1973, mayo 6).

Destituido Bautista, fue nombrado gobernador interino Guillermo Morales Blúmenkron, quien el día en que tomó posesión hizo un llamado a todos los sectores sociales para buscar la unidad. Por la tarde recibió al Consejo Coordinador Empresarial que le pidió no tolerar la intromisión de los comunistas en la Universidad, porque a ellos se debía lo que había ocurrido. A continuación se transcribe un párrafo de los cuatro puntos del desplegado que apareció publicado en un cuarto de plana en un periódico local:

Protesta permanente contra el caos comunista.

1. Protestamos porque los estudiantes muertos el $1^{\circ}$ de mayo que todos lamentamos, no se hubieran producido si los dirigentes del Partido Comunista que detentan la dirección de la UAP no hubieran armado a estos jóvenes y los hubieran llamado a disparar a la Policía (como demostró la prueba de la parafina), (El Sol de Puebla, 1973, mayo 11).

Pero las fotografías, que ya circulaban, mostraban fehacientemente desde dónde habían disparado los francotiradores con armas de alto poder. En una de ellas aparece el agente de la policía estatal apodado El Chisín en una torre de la Catedral, a dos calles y media de la Universidad. Sin embargo, el gobernador negó que hubiera mandado a este grupo paramilitar. La prensa local insistió en que los estudiantes habían sido quienes provocaron la violencia; más aún, acusaron al profesor Alfonso Calderón Moreno de lo ocurrido. Pero Calderón había sido herido por El Chisín y más tarde moría:

Murieron en el interior de la Universidad, por disparos de armas de fuego: Enrique González de 20 años de edad, estudiante del tercer año de Ingeniería Química, y Víctor Manuel Medina, estudiante del segundo año de la Preparatoria Enrique Cabrera. Posteriormente, a las 0.00 horas en el Hospital Civil Universitario, falleció Alfonso Calderón, considerado por la policía como el principal instigador del conflicto y que recibiera dos heridas en el cuello (El Sol de Puebla, 1973, mayo 2).

Ana María Moreno de Calderón, madre de Alfonso Calderón Moreno, lo alcanzó a ver herido en el Hospital Universitario, al que fue llevado. Minutos después lo vio morir. El asesinato de su hijo impulsó de manera decidida y entregada a la señora Ana María. Ella con la familia (la esposa de Alfonso; Miguel, su otro hijo y el padre de 
Alfonso) exigía el esclarecimiento de los hechos; asistía a las reuniones del Consejo Universitario y a todas las actividades programadas para denunciar lo ocurrido, prosiguió con la lucha y apoyó el movimiento.

Junto con varias mujeres organizaron un mitin el 10 de mayo, por la tarde, para exigir: "Aclaración de los asesinatos de universitarios y castigo a los responsables" (El Sol de Puebla, 1973, mayo 11). Por supuesto que la nota sobre este mitin fue muy pequeña, comparada con la nota del otro mitin al que convocó un supuesto "Comité de Madres de Familia” para el 11 de mayo, en el que acusaron a los comunistas de manejar la Universidad; además se publicó un desplegado de media plana donde estas "madres de familia” pedían no llevar a sus hijos a esta Universidad.

Los días siguientes los universitarios redoblaron esfuerzos para difundir y dar a conocer lo que en realidad había sucedido. Mientras, al interior de la Escuela de Arquitectura se dirimían las diferencias sostenidas de tiempo atrás entre los FÚAS y los miembros del comité de lucha.

Las presiones a las jóvenes eran fuertes; debían decidirse por una opción y no todas estaban politizadas. Los FÚAS llegaron al extremo y propusieron dejar la Universidad porque estaba bajo el mando de los comunistas. La división llegó al clímax y la mayoría de profesores salieron y fundaron la Universidad Popular Autónoma del Estado de Puebla, UPAEP, institución privada que desde ese momento asumió una ideología católica de derecha. La división en la Escuela de Arquitectura reflejaba lo que ocurría en un contexto social alentado por el anticomunismo. Días después, el 18 de mayo, en un desplegado la UPAEP publicaba que iniciaría clases el 4 de junio.

A pesar de esto, la mayoría de las estudiantes de Arquitectura optó por continuar estudiando en la UAP, aun corriendo el riesgo de quedarse sin clases porque la mayoría del profesorado se había ido. Fue la oportunidad para quienes, casi terminada la carrera, se convirtieron en docentes en la Escuela de Arquitectura.

El reconocimiento de la nueva universidad por la Secretaría de Educación Pública se decretó antes de que se aceptara la renuncia del gobernador Bautista O'Farril, por lo que todos los desplegados contra los comunistas que manipulaban a la UAP, firmados por el Consejo Coordinador Empresarial, la Federación de Barrios y Colonias de Puebla, el Comité Coordinador Permanente de la Ciudadanía del Estado de Puebla, la Asociación Cívica y otras organizaciones, sirvieron como propaganda para alentar a los jóvenes a inscribirse en la naciente UPAEP. 


\section{Conclusiones}

En el movimiento estudiantil, conocido como la segunda Reforma Universitaria, se visibilizan la participación de las mujeres, en la que, como lo señala Gabriela Cano "En la visión androcéntrica presente en la historiografía mexicana, las mujeres aparecen como caso especial y muchas veces marginal de una historia masculina definida como 'general'. Se les toma en cuenta ocasionalmente cuando invaden espacios de varones y en consecuencia se les analiza con los criterios utilizados para éstos" (Cano, 1994, p. 424).

Esta investigación, apoyada, en consulta hemerográfica, documentos y testimonios, muestra cómo se inscriben las universitarias en un movimiento estudiantil, en el que tuvieron que romper con una educación tradicional y transgredieron normas. Los tres momentos analizados corresponden al año 1973, aunque la virulencia contra la Universidad se incuba antes. La riqueza de la historia oral permite mostrar, lo que propone la historiadora Ana Lau Jaiven: "Reconstruir la historia de un grupo de mujeres no significa hacer la descripción de algunos eventos que han sido importantes en sus vidas, más bien se trata de acercarnos al espacio concedido a las representaciones sociales, ámbito relacionado con el cuerpo y todo lo que a través de él se expresa y se vive" (Lau, 1998, p. 190).

En este sentido las entrevistas a las que se acudió en este estudio reflejan lo que una generación vivió: la violencia física, verbal, en la prensa, dentro y fuera de los recintos universitarios. La intensidad de esta confrontación, que llegó al extremo de que la ciudad fue acordonada por policías y granaderos, no evitó su compromiso con la institución. Esto significa que las estudiantes se incorporaron a los espacios de la política y se vincularon no sólo con el movimiento estudiantil, sino con el movimiento popular que se desarrollaba.

Las universitarias de la generación de los setenta vivieron un activo movimiento estudiantil cuya base descansaba en los comités de lucha y habían ganado ya lugares de representación en el Consejo Universitario, la máxima autoridad. La violencia con la que se atacó a la Universidad terminó de convencer a muchas de la defensa de la institución y de la necesidad de apoyar una Segunda Reforma Universitaria. El reconocimiento de nuevas carreras, escuelas y dependencias universitarias y de cada logro del movimiento universitario las involucró más. 


\section{Referencias}

Cano, y Radkau (1994). Lo privado y lo público o la mutación de los espacios (historia de mujeres, 1920-1940). En Vania Salles y Elsie Mc Phail (Coord.). Textos y pre-textos. Once estudios sobre la mujer, México, El Colegio de México, Programa Interdisciplinario de Estudios de la Mujer.

Cano, S. G. (2005). Entrevista. Junio 6.

Curro, M. (2001). Entrevista. Noviembre 18.

El Sol de Puebla (1971). Medicina, la carrera más solicitada por mujeres. 4 de agosto.

El Sol de Puebla (1973). Alumnos de nuevo ingreso. 5 de enero,

El Sol de Puebla (1973). Balacera entre estudiantes y policías. 2 de mayo.

El Sol de Puebla (1973). Exhorta el arzobispo a la paz y concordia. 6 de mayo.

El Sol de Puebla (1973). Otro mitin y manifestación de madres de familia en la UAP. 11 de mayo,

El Sol de Puebla (1974). "Sección Culturales. 14 de agosto, p. 4

Lau, A. (1998), "Cuando hablan las mujeres". En Bartra (Comp.). Debates en torno a una metodología feminista, México, Universidad Autónoma Metropolitana, Unidad Xochimilco.

RIVAs, O. (2007). La izquierda estudiantil en la UNAM. Organizaciones, movilizaciones y liderazgos (1958-1972). México: UNAM, Miguel Ángel Porrúa.

Scott, J. (1992). El problema de la invisibilidad. En Carmen Ramos Escandón (Comp.). Género e historia, México: Instituto Mora-UAM, Antologías universitarias.

Sotelo, H. (2002). 1972-1973, Puebla de los demonios, Puebla: Gobierno del Estado de Puebla, BUAP, Cuadernos del Archivo Histórico de Puebla. 
Tirado, G. A. (2014). A cuarenta años del movimiento estudiantil. Universitarias de los años setenta en la Universidad Autónoma de Puebla, México. En Esaú Márquez Espinosa y María del Rocío Ortiz Herrera (Coords.). Sociedades encauzadas: geografia, historia y realidad (pp. 373-389). México: Universidad de Ciencias y Artes de Chiapas,

Tirado, G. A. (2004). La otra historia. Voces de mujeres del 68, Puebla, México: BUAP-Instituto Poblano de la Mujer.

Tirado, G. A. (2015). Experiencias con fuentes orales para el estudio de las mujeres en los movimientos estudiantiles. En Josué Mario Villavicencio Rojas, Blanca Esthela Santibáñez Tijerina. Acervos regionales en la construcción histórica (pp. 113-148). Instituto de Ciencias Sociales y Humanidades, Fomento Editorial, BUAP.

Universidad de Puebla (1973, sesión del 3 de mayo). Actas del Consejo Universitario.

Vidales, M. L. (2015). Del silencio al testimonio: las estudiantes en el contexto de la insurgencia estudiantil en la Universidad Autónoma de Sinaloa. En Perspectiva de género. Historia, actualidades y retos desde una óptica interdisciplinaria. México: Universidad Autónoma de Zacatecas, Universidad Autónoma de Querétaro, UNAM, Universidad Autónoma de Aguascalientes.

Valcárcel, A. (2013). Feminismo en el mundo global, España: Ediciones Cátedra, Universitat de Valencia, Instituto de la Mujer.

Yánez, A. (1988). Reforma y violencia, Puebla: Universidad Autónoma de Puebla. 